University of Wollongong

Research Online

Faculty of Business - Papers (Archive)

Faculty of Business and Law

$1-1-2014$

Local government service systems improvement: exposing the social networks

Matthew Pepper

University of Wollongong, pepper@uow.edu.au

Andrew Sense

University of Wollongong, asense@uow.edu.au

Follow this and additional works at: https://ro.uow.edu.au/buspapers

Part of the Business Commons

Research Online is the open access institutional repository for the University of Wollongong. For further information contact the UOW Library: research-pubs@uow.edu.au 


\title{
Local government service systems improvement: exposing the social networks
}

\begin{abstract}
Using a local government (LG) case study, this paper describes and qualitatively explores the value and use of social network analysis (SNA) in creating a rich environment for service network innovation and development. The case study analysed manages regional planning development applications and involves a complex social network. The study underpins the view that in LG service environments, mechanistic models for systems improvement are on their own inadequate. SNA constitutes an essential complementary development framework underpinning continuous innovation through human and social capital development. Findings presented are profound for local government and multiple service contexts and argue for a greater emphasis on understanding and developing the human and social aspects of service systems as opposed to a predominant technical systems bias.
\end{abstract}

\section{Keywords}

local, social, government, networks, service, systems, improvement, exposing

Disciplines

Business

\section{Publication Details}

Pepper, M. \& Sense, A. J. (2014). Local government service systems improvement: exposing the social networks. Journal of Management and Governance, 18 (3), 873-890. 


\title{
LOCAL GOVERNMENT SERVICE SYSTEMS IMPROVEMENT: EXPOSING THE SOCIAL NETWORKS
}

\author{
Dr Matthew Pepper \\ Lecturer \\ Institute for Innovation in Business and Social Research \\ School of Management and Marketing \\ Faculty of Commerce \\ University of Wollongong \\ Wollongong, NSW, 2522, Australia \\ Tel: +61 242215419 \\ Fax: +61 242272785 \\ E-mail: pepper@uow.edu.au \\ Dr Andrew Sense \\ Associate Professor \\ Institute for Innovation in Business and Social Research \\ People and Organisation Research Centre \\ School of Management and Marketing \\ Faculty of Commerce \\ University of Wollongong \\ Wollongong, NSW, 2522, Australia \\ Tel: +61 242214723 \\ Fax: +61 242272785 \\ E-mail: asense@uow.edu.au
}

\begin{abstract}
Using a local government (LG) case study, this paper describes and qualitatively explores the value and use of social network analysis (SNA) in creating a rich environment for service network innovation and development. The case study analysed manages regional planning development applications and involves a complex social network. The study underpins the view that in LG service environments, mechanistic models for systems improvement are on their own inadequate. SNA constitutes an essential complementary development framework underpinning continuous innovation through human and social capital development. Findings presented are profound for local government and multiple service contexts and argue for a greater emphasis on understanding and developing the human and social aspects of service systems as opposed to a predominant technical systems bias.
\end{abstract}

Keywords: Social networks; Social network analysis; Service Innovation; Capability Improvement 


\section{Introduction}

The service sector constitutes a significant part of national economies, and will continue to increase in size and complexity as both the service and manufacturing sectors are forced to differentiate to remain competitive within a global market. Service industries are striving to adopt improvement initiatives (Piercy and Rich, 2009; Antony, 2006), and their service systems are increasingly becoming the key focus of organisational improvement activities to better exploit gaps in customer perceptions of quality and service delivery in the market place.

Such service innovation can be viewed in the public sector for example as the development of 'innovative...policy... and services, tailored to the needs of citizens' (Australian Government Report, 2010 pIII). This need for continuous improvement in order to deliver tailored services to customers requires organisations to rethink their existing approaches to work practices. That is, 'For innovation to become embedded...it will mean changes in behaviour, organisational models and bureaucratic processes and culture' (Australian Government Report, 2010 p62). Clearly, as is also suggested in this paper, this implies that the social systems in service organisations are also a crucial part of the innovation solution and the systematic design and development of customer focused service provision. More generally, to aid such innovation activities, it is therefore appropriate to increase our understanding of what is service provision (Johnston, 2005) and to explore how service industries pursue improvement initiatives (Prajogo, 2007). In partial support of such knowledge and practice innovation development, a steadily growing body of literature in the services field informs us about the transferral and adoption of operations management perspectives and techniques. This literature examines and demonstrates how these techniques may be applied to achieve improvements and to gain and sustain competitive advantage in the service environment (Roth and Menor, 2003; Johnston, 2005; Prajogo, 2006; Correa et al., 2007). For example, process mapping is one such operations management technique that has seen good exposure in the services environment. It is a visual approach to charting and understanding business systems as a preliminary stage to improvement activities and involves the modelling of process activities, people and information required to produce a particular output (Biazzo, 2002). Traditionally, the system being mapped is deconstructed into discrete processes and presented as a diagram of sequenced activities. Management are then required to understand 
and analyse the system, before eliminating any activities that do not add value to the production of the specified output (Wisner and Stanley, 2008) and, based on various business improvement philosophies, improve the remaining value-adding processes.

To varying degrees and consistent with Ackoff's (1999) view that it is essential to appreciate the interactions between the individual parts of an organisation, most service systems rely on both technical and conjoined social systems working in harmony to provide a quality and timely service. However, to date, the identification and practical use of techniques to better exploit and innovate service systems has focused primarily on the development of the technical elements that appear to be more tangible, identifiable and seemingly more amenable to development e.g. information systems (Fung and Wong, 1998; Chow, 2004) and process redesign (Piercy and Rich, 2009). In some part, any ignorance or deliberate avoidance of the social networks is understandable given that in comparison to technical systems they appear and act less rationally, are less comprehensively identifiable and are certainly less predictable. Compounding this issue, the boundaries of the attendant social networks in a system appear less distinct and most often transcend discrete technical processes, resulting in difficulty when determining agreed boundaries for analysis. For example, in the traditional process mapping technique, whilst process visibility and understanding is definitely assisted (Klotz et al., 2008), the scope to achieve a more comprehensive and holistic systems view and improvement in service operations is often neglected or downplayed. Joiner (1994) describes this necessity of maintaining a more balanced view within improvement philosophies as a balance between the cultural, technical and the required outcome (i.e. the quality to be realised). It can be reasonably suggested that traditional process mapping has a tendency to focus only on the technical aspects and the required outcome. In addition to impacting the adoption and performance sustainability of any technical improvements, it is this exclusion or ignorance of the social networks (that are intrinsically found in both face to face and electronic service provision) from any service redesign process that severely limits the scope of system understanding and thus also, the scale of what can potentially be achieved with a redesign that accounts for an entire service system.

Our acknowledgement of these social system issues/opportunities in any service environment does not suggest for one minute that organisations do not pay attention to developing individuals or groups to perform their roles and functions appropriately, as that would be rather naïve. Instead, what we posit in this paper is that organisations need to first engage a 
holistic systems perspective in improving service delivery, and second, also need to place more emphasis on understanding and exploiting the social networks for service systems improvement. We acknowledge that this general argument is not necessarily new in some fields of literature. For example, this dual focus has been particularly argued for in the sociotechnical systems literature (see for example, Taylor and Felton (1993) and Cotter (1995)), the quality management literature (see for example, Joiner (1994) and the seminal work of Deming (2000)), the project management literature (see for example, Sense (2007) and (2009)) and also in more recent supply chain literature that articulates the necessity of developing inter-organisational social relationships and systems for improving supply chain performance and innovation competency (see for example, Min et al. (2005), Gattorna (2006), McGarth and Sparks (2005), Zaklad et al., (2004), Sense and Clements (2007) and (2010)). While embracing these ontological perspectives, what is critically different with the analysis provided in this paper is that it builds upon the literature surrounding operational improvement (Yang et al., 2007) and we qualitatively argue for (and empirically illustrate using a local government case) the value and use of social network analysis (SNA) in better understanding the social relationships in a service system. In doing so, one is better informed and more appreciative of the dynamics of the social relations involved and can thereby facilitate a richer environment for service innovation and development. Thus, our position is clearly human-centred but should be viewed as complementary to traditional technical system approaches. In essence, our paper provides an insight into how one can better understand and subsequently better engage with the social systems in service operations.

To achieve its aims, this paper first explores the theoretical frameworks informing the study. The next section then outlines the methodological approach engaged and the case study examined. Thereafter the findings are presented and inferences drawn, as well as the implications for research and practice expounded. The final section brings together the key themes established in this paper and articulates the limitations of this study and offers directions for future research.

\section{Theoretical framework}

This study is guided by a social constructivist epistemology and primarily informed by systems theory and socio-technical systems theory. Two distinct aspects of systems theory have long been discussed in academic literature. The first of those involves the pioneering 
work of Soft Systems Methodology (SSM) (Checkland, 1981), whereby the emphasis lies in learning about interactions between the system itself and the system boundaries, and acknowledging the fact that people and organisational influences cannot be separated from decision making processes (Maani and Cavana, 2007). The soft systems approach views organisations as dynamic and complex entities, directly influenced by the people within them (Attefalk and Langervik, 2001). In particular therefore, SSM strongly resonates with the focus of our paper, given its emphasis on the richness of the socio-technical system (Ingram, 2000). The second aspect involves Systems Dynamics (Forrester, 1999; Sterman, 2000). This considers systems as complex and dynamic entities and focuses on the modelling and understanding of interactions between elements within systems. Clearly too, this aspect has direct relevance to this study and the arguments posited in this paper and has reinforced the necessity to interpret service systems as complex and dynamic socio-technical entities. In sum, systems theory has focused our attention towards the entire system rather than discrete parts, and in so doing, particular emphasis is placed on the dynamic social networks involved.

Socio-technical systems (STS) theory is generally well acknowledged and stems from the research work of the Tavistock Institute (i.e. Trist \& Bamforth, 1951) into the work and organisation design of coal mining in the UK in the 1950's. STS as a philosophy stresses a systems focus, empowerment of people, focus on product and organisational wide clarity of purpose (Taylor and Felton, 1993) which is a significant departure from the mechanistic Taylorist (2007) approaches seen in earlier decades in manufacturing organisations. STS also recognises that there are two systems in play in any organisation i.e. the technical and social systems and both need to be independently and in interaction understood and developed. To achieve such aims, authors including Taylor and Felton (1993), Cotter (1995), Pfeffer (1995) and Cherns (1976), articulated methods to diagnostically investigate or understand these systems. One typical method employed is to perform a social network analysis which involves identifying a role network, then developing a social system grid and assessing the quality of work life of participants (Taylor and Felton, 1993). When combined with a technical systems analysis, organisational participants have the opportunity to jointly optimize the re-design of their entire system - although any tools to effectively achieve such outcomes are not defined, therefore, the joint optimization process appears more of an iterative sensemaking and creative process. In the case study examined, social network mapping aspects of STS are fundamental in understanding the communication and network relationships existing between the stakeholders involved. STS theory and methods have both 
conceptually informed and practically guided our approach (and indeed underpin our arguments) in this study. As such, this paper also makes a further empirical contribution to this literature in that it provides an illustration of the value of mapping the social networks for addressing real and significant service challenges.

\section{Methodology and Study Context}

Case Study Methodology. Using a hybrid mapping technique that combines process mapping and key elements of social network analysis or 'interaction patterns' as described by Cotter (1995), a case study investigation was undertaken in a local government entity. The case was selected and considered a highly appropriate vehicle for this intended study, due to the perceived complex nature of the communication patterns, interdependencies and interactions surrounding each process step and the number of potential stakeholders involved (internal and external to the agency). Within that complexity lay opportunities for identifying social connections/interactions that may have provided avenues to improve the service system performance and innovation capability. These interactions can be formal (such as official meetings, letters, emails etc.) or informal (informal meetings, gatherings, phone calls etc.) in nature.

The researchers were also made aware of these opportunities prior to undertaking the project since they had a prior research association with the agency involved and consequently too, they had the necessary support of the agency to access all the stakeholders involved. Thus, this case was accessible and considered by the agency representatives to be quite typical of a complex service process that every other LG institution engages with. Moreover, the focus of the study is concerned with the broader issue and arguments of engaging with social network analysis as a means to help improve the quality and timely delivery of services to customers. The case used serves to illustrate that broader intention, and in so doing, the findings from this case may have utility and value across similar organisational settings and contexts in which interactions/communications are central to the system because of the need for negotiation between parties to achieve a mutually agreed outcome.

Case studies are considered particularly desirable in applied social science, where the research aims to provide practitioners with tools (Gummesson, 1991) and learning opportunities [for both practitioners and the academic researcher audiences] in preference to 
confirming hard theory (Flyvbjerg, 2001). Yin (1994) also suggests case studies are the preferred strategy when 'how' or 'why' questions are being posed or when the investigator has little control over events, and where there is the desire to understand complex social phenomena. Eisenhardt (1989) suggests that case studies are intimately tied to empirical reality and therefore empirical evidence (including the contextual conditions), and it is this intimate connection that permits the development of a testable, empirically grounded theory. Our case study represents a single revelatory case (Yin, 1994) which presented numerous 'how' and 'why' questions about real-world practice communication issues in the social networks of a service system. In some disciplines this singular focus on a case is considered to be problematic for theory generation. However, in applied social science theory and in broad concurrence with Gummesson (1991) and Yin (1994) perspectives, Flyvbjerg (2001, p73) concludes that, 'Predictive theories and universals cannot be found in the study of human affairs. Concrete, context dependent knowledge is therefore more valuable than the vain search for predictive theories and universals'. Therefore, case studies provide opportunities to more deeply explore situations and to generalize to theoretical propositions rather than universal theories that apply across a population (Yin, 1994). In respect to the research methods engaged in this case study, they involved long semi-structured explorative interviews with various system stakeholders, historical documentation collection and analysis and processual observation of internal council processes. These data were collated, thematically analysed and key findings inductively developed. In particular, the data analysis concerning the social relations between parties involved critical assessment on what matters did they converse, the frequency and prevalent direction/s of those communications, and their perceptions of the formality or informality of each - as conveyed through the interview processes and observations undertaken. The researchers then inductively determined the relevance of the interview data to the social interactions within the setting, the relative severity of those interactions and whether or not they were formal or informal in comparison to established system protocols.

Study Context. Like many other regional authorities worldwide, local governments in Australia are under continual pressure to lift performance in response to their constituents' needs and expectations of efficiency, sustainability, participation and social equity. Increasingly, this has had to be achieved with decreasing funding support from State or Federal governments and increasing restrictions on local government capacity to raise revenues from ratepayers. This study involved a local government entity called 'agency Z' 
(Z) which is embroiled within this new operating milieu. $\mathrm{Z}$ is a large local government authority in Australia providing corporate planning, development, environment protection, infrastructure and community services to its region. One of many important and significant services provided to its regional community involves development applications (DA) and their approval processes, where processing lead times are a key performance indicator. These DAs can range from small residential development applications e.g. erecting a garage, to large subdivisions in newly released land to multistorey office towers in the central business district. Like other councils in the state, $\mathrm{Z}$ is only authorized to approve DAs up to $\$ 100$ million in value. Applications worth more than $\$ 100$ million are eligible for approval by the Department of Planning, at the higher State Government level. This will incur a different regulatory regime due to the significance of the investment and the potential impact on infrastructure. The case study involves the department of city planning within $\mathrm{Z}$ which is responsible for the assessment and determination of eligible DAs. In addition, the department provides pre-lodgement consultation to the applicants in the form of pre-lodgement meetings, telephone enquiries, face to face meetings and organized consultations. These consultations are formal in nature and at this process stage no indications are provided on the determination of the applications. Council's professional code of conduct prohibits the council officers to conduct any informal meetings with the applicants in order to preserve the transparency and integrity of the pre-lodgement process. The development applications have to go through a network of pre-lodgement processes and a wide range of stakeholders before formal lodgement at the council. Each DA goes through four process stages, namely (i) application initiation, (ii) pre-lodgement meeting, (iii) application preparation (iv) application lodgement (Bhagat et al., 2009). Stages (ii) and (iii) are not necessarily sequential as activities undertaken within each stage may overlap.

The second stage (pre-lodgement meeting) is a service offered by $\mathrm{Z}$ as a discussion forum regarding a proposed development, between the external (e.g. applicant) and internal (i.e. experts within the agency) stakeholders. The discussion will be based on any plans, technical information and any other relevant supporting documentation previously provided by the applicant. The aim of these meetings is to discuss any issues relevant to the application (location, environmental impact etc.). The intention is to provide advice based on the submitted documentation, and if necessary pose suggestions for a particular element of the application that is unacceptable. It should be noted however, that the meetings are for advisory and clarification purposes, and do not culminate in an approval decision. The 
internal and external stakeholders range from numerous persons working in council departments such as city works, traffic and urban design, the applicants, finance agents, consultants, architects and developers, property agents and a range of external referral agencies such as departments of environment and conservation, national parks authorities and other state government planning departments as required. Only those stakeholders that are directly relevant to the specific application attend the meeting. Parallel to this, the application preparation begins when an applicant lodges a request for a pre-lodgement meeting with the Customer Service Officer (CSO), in effect overlapping in time, rather than being completely sequential. This is due to the fact that applicants begin to gather information and proposals etc. to be discussed at the pre-lodgement meeting while waiting for a date to be confirmed. The officer checks that all relevant documents and fees have been submitted, before issuing a DA number to the applicant and passing the information to the Preliminary Assessment Unit (PAU). The PAU then reviews the documentation, and if the relevant fees have been paid, the unit begins the coordination of the pre-lodgement meeting.

Agency $\mathrm{Z}$ acknowledged that some stakeholders perceived there were problems concerning long DA turnaround times, one way communications during the assessment stage, and the quality of advice received in the pre-lodgement meetings. The broader implications of these issues potentially manifesting as a loss of development projects within the region with flowon effects on employment opportunities, regional development and income. In sum, our case study focused on the overarching pre-DA lodgement system in which we mapped and interpreted the service processes and the attendant social communications and interaction patterns between stakeholders involved.

\section{Findings and Analysis}

The social networks surrounding each of the key stages of the DA system examined in this study provide a rich and more holistic understanding of the otherwise invisible interactions and causal relationships contiguous with the service system examined. To aid the efficient dissemination and illustration of our findings we have elected to focus our analysis and discussion in this paper on two key stages of the DA system - the Pre-lodgement Meeting (PM) and the Application Preparation (AP) processes. In developing the social network maps, and following the notation described by Cotter (1995), communications between stakeholders are separated into four categories: weak informal (infrequent), strong informal (frequent), 
weak formal (infrequent) and strong formal (frequent). Informal communications are depicted as broken arrows, while formal communications are depicted as solid arrows. In all cases, the direction of the arrow indicates in which direction information flows and where the communications originated. The frequency of communication is depicted by the width of arrow (a thick arrow equates to a high frequency of communication and vice versa). However, one first needs to establish the service process map which depicts the back office and front office activities (Krajewski et al., 2010) involved in providing the service to the community.

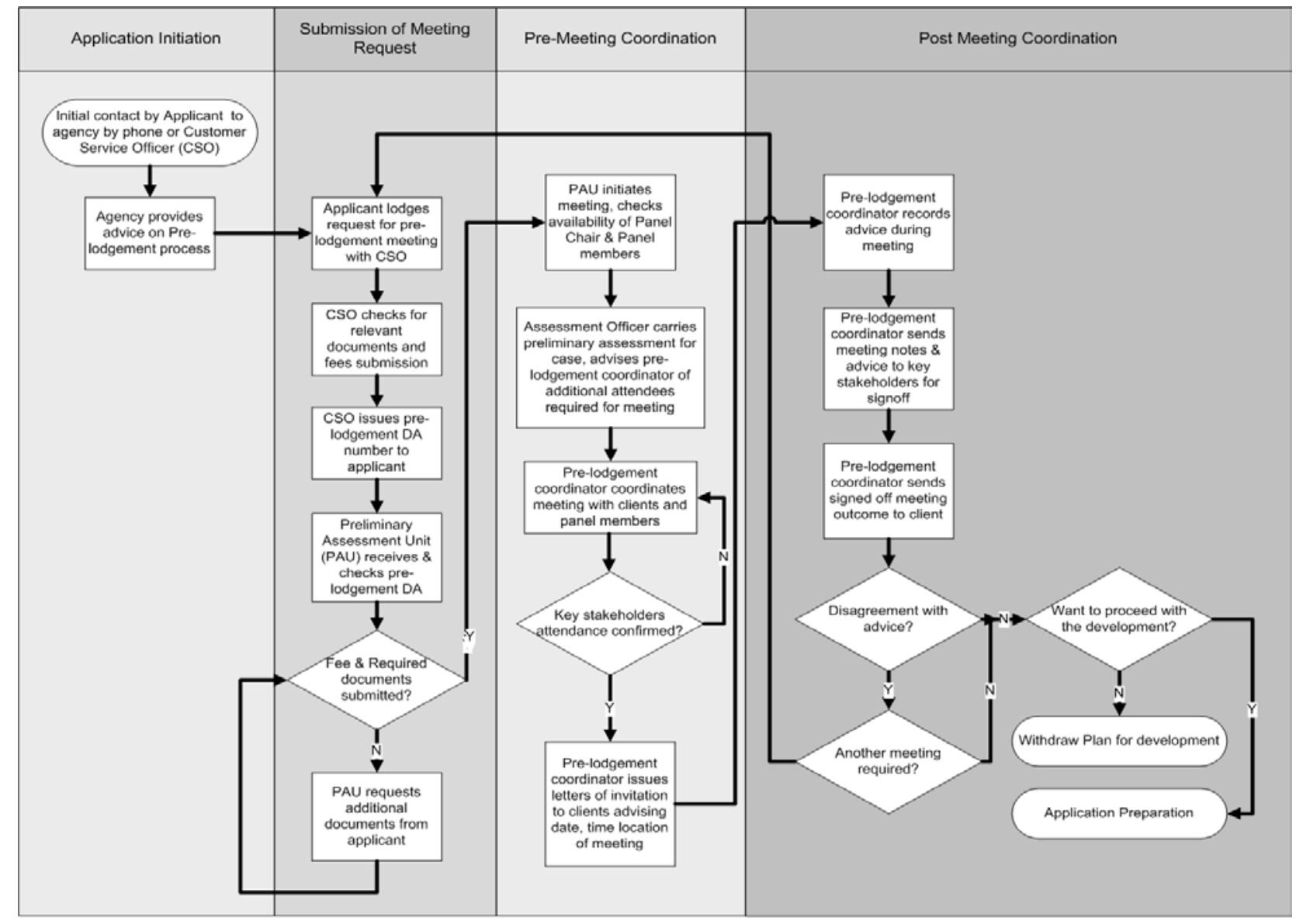

Figure I. Pre-lodgement Meeting Process Map

(adapted from Sense and Pepper, 2012)

Figure I, depicts the process map for the Pre-lodgement Meeting (PM), describing all process activities and decisions that are undertaken. This entire map represents a preparatory phase involving both formal and informal activities prior to any formal DA submission process. The 
PM provides a formal opportunity to discuss concerns with a development application prior to its official lodgement. The attendees include: the applicant, external consultants, Prelodgement Co-ordinator, who is a member of the Preliminary Assessment Unit (PAU), Development Planning Officer (DPO), Development Manager, referral officers and external officers relevant to the specific application. The Pre-lodgement meeting process can be subdivided into four stages (as depicted in Figure I): pre-lodgement meeting advice, lodgement and assessment, pre-meeting coordination and post meeting coordination. The process begins when the applicant makes initial contact with the agency, seeking advice for pre-lodgement meeting preparation. Once this request is lodged, a customer service officer checks the submission, and issues a DA reference number to the applicant. A Pre-lodgement Co-ordinator schedules and organises the meeting. Once the meeting has taken place, the coordinator distributes minutes and recorded advice to the attendees.

Figure II, below, shows the corresponding communications and interactions associated with the stakeholders for the full process depicted in Figure I. A complex array of interactions takes place, which are not captured within traditional process mapping approaches and which critically inform decision making in the service system. The frequency and formality (or informality) of communications between stakeholders are clearly depicted, highlighting critical communication hubs on the process map. In this case, the Pre-lodgement Coordinator and the Applicant constitute the focal points or hubs for most of the communication activities at this stage in the process. This social network operates across the entire process illustrated in Figure I. Thus, the highlighted focal roles (Pre-lodgement coordinator and Applicant) and attendant communications are in play across all processes within the system and are therefore, not confined to any particular process activity. Additionally, these communications reflect the aggregated opinions and experiences of the stakeholders over the course of a number of engagements with the DA processes and are not simply representative of one singular event. Thus, as depicted these communications indicate system trends and biases that exist within the social network. 


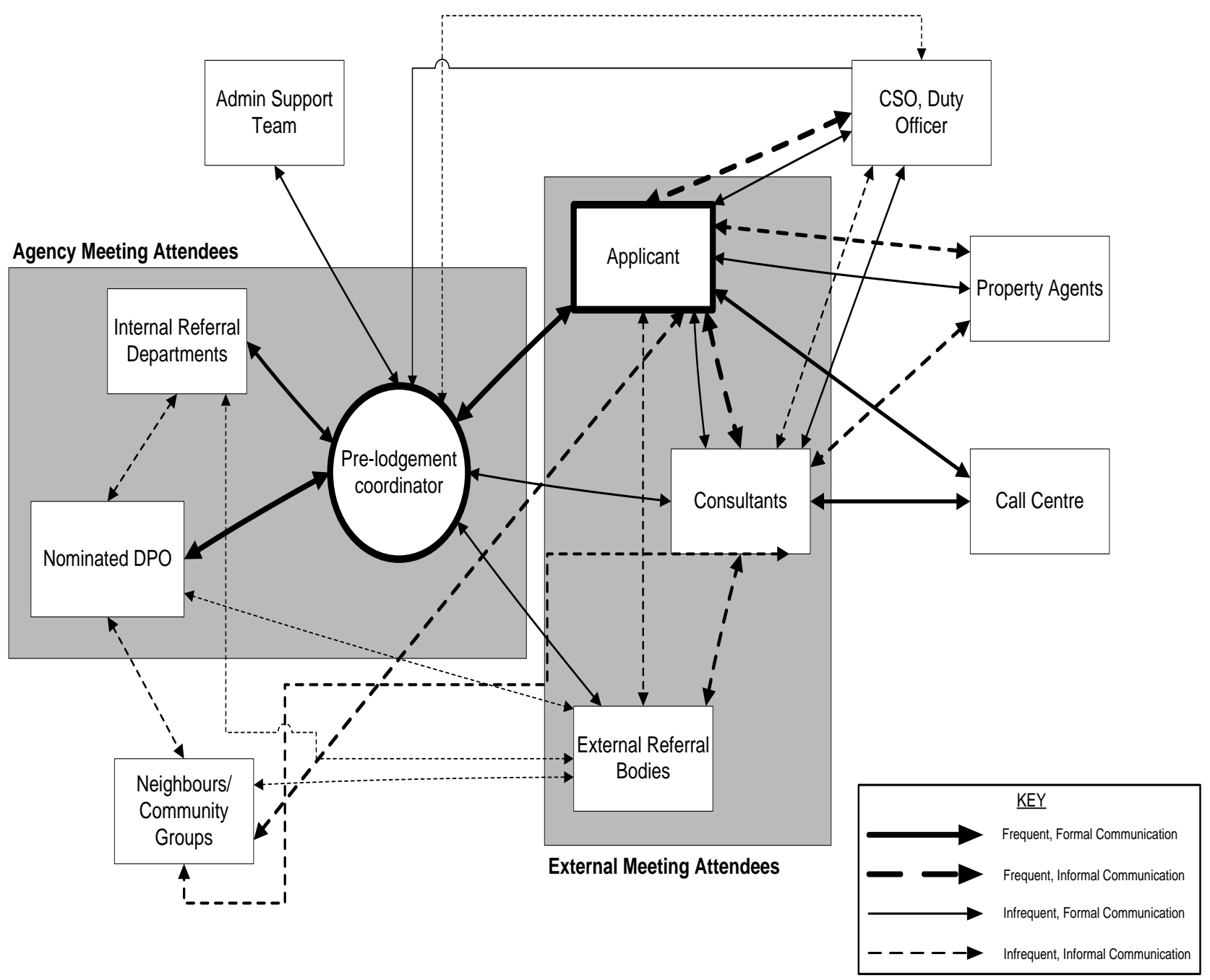

Figure II. Pre-lodgement Meeting Social Network

(adapted from Sense and Pepper, 2012)

The communication patterns between external and internal stakeholders (or meeting attendees in this case) at this stage of the DA system are clearly depicted in Figure II. One can observe there are multiple two way communications occurring between the external and internal stakeholders (Agency Meeting Attendees) visible in the shaded zones respectively in Figure II) with the majority being informal (informal meetings, phone calls, gatherings etc.). This situation is primarily driven by consultants, almost at the exclusion of other stakeholders. This is in an effort by the consultants to "strengthen their communications" (Bhagat et al, 2009, p10) and manage frustration at perceived 'poor turnaround times' and thus accelerate decisions from agency Z. This often intensive pursuit of informal communication channels does adversely affect the process and is reported by agency $\mathrm{Z}$ to increase workload and system variation. 
Agency Z identifies four key system variations created by this informal communication from both internal and external stakeholders. Namely, (i) inefficient use of agency resources in that agency $\mathrm{Z}$ staff still find themselves responding to frequent and ad hoc requests, (ii) inefficient use of resources specifically related to the Pre-lodgement Meeting (PLM) (iii) incomplete or inaccurate applications from external stakeholders - something which the PLM process is meant to address and channel formally (iv) the quality of advice that agency $\mathrm{Z}$ is able to provide stakeholders also varies due to limited or even inaccurate information provided to them informally by the same or other external and internal stakeholders. Informal communication could be culpable as an audit trail is lacking for accountable actions or advice. Informal (i.e. unmonitored and unwieldy) communications are also thought to be at greater risk of corruption or deviance in that unfair or biased outcomes can be negotiated. This is due to the lack of visibility of interactions between parties both internal and external. Ultimately, agency $\mathrm{Z}$ perceive an increase in their system lead time due to these informal communications contributing to the multi-handling of applications. For example, this may involve applications that require revision or additional meetings/administration to progress. Additionally it is considered by some agency representatives that the agency's minimal formal involvement perpetuates informal communication cycles which inhibits the PLM process.

In sum, in this case these informal communications are significant because of who is instigating them - consultants on behalf of the applicant, meaning they have a vested interest in expediting the process in their favour. As one stakeholder in the research acknowledged, "although the informal communications between agency staff and consultants is discouraged, the consultants make it a point to get information from all possible sources which is essential for them to carry on their business". Thus, this depicted 'informality' highlights a potential (and otherwise hidden) risk profile within the system concerning increased system variability. The reduced visibility of communications and subsequent difficulty in auditing the (social) system to ascertain any causes of service system variability is clearly problematic. Moreover, in the context of this service system case, a government regulated environment, the agency's own code of conduct mandates 'accountable communication' to ensure corporate transparency and ethical standards of behaviour. The social network analysis has revealed however, communications still take place informally between stakeholders, making this goal more difficult to realise in current practice. 
Notably, the SNA has revealed that no communication takes place between the prelodgement co-ordinator and community groups. This may have some impact on system performance given that the quality of the pre-lodgement meeting content is quite dependent on the quality of the communications and data gathering efforts made by the applicant. One can speculate that a more proactive formal communication structure between the Prelodgement Coordinator and community groups for example, might better assist more thorough and timely information exchange on these matters rather than perhaps furnish a sanitized version being posited by the applicant.

On a broader scale, it is also tentatively considered that the lead time of the DA process could be reduced if agency $\mathrm{Z}$ could more actively participate (formally) in the informal social network - given these networks consume much time. That is, by intervening more actively agency $\mathrm{Z}$ may have the opportunity to accelerate the DA process through re-organizing communication channels that better encourage and collate necessary information in a more efficient manner, or at least provide clarity to applicants in order to negate the need for much of the informal communication which occurs from seeking progress updates or information Much of the informal communication identified here results from applicants' anxiety over the perceived complexity of the process, and consultants attempting to 'seek information and maintain perceived relationships' with agency staff (Bhagat et al,, 2009 p11). Any such increase in participation, feedback and sharing of knowledge between stakeholders could also help foster a common clarity of system purpose and transparency of expectations throughout the service network - led by the agency providing the service. These inferences are not the focus of this paper and are yet to be tested in practice. However, they provide some interpretations of possible system changes and arguably at the least, form the basis of further discussions between the parties involved. 


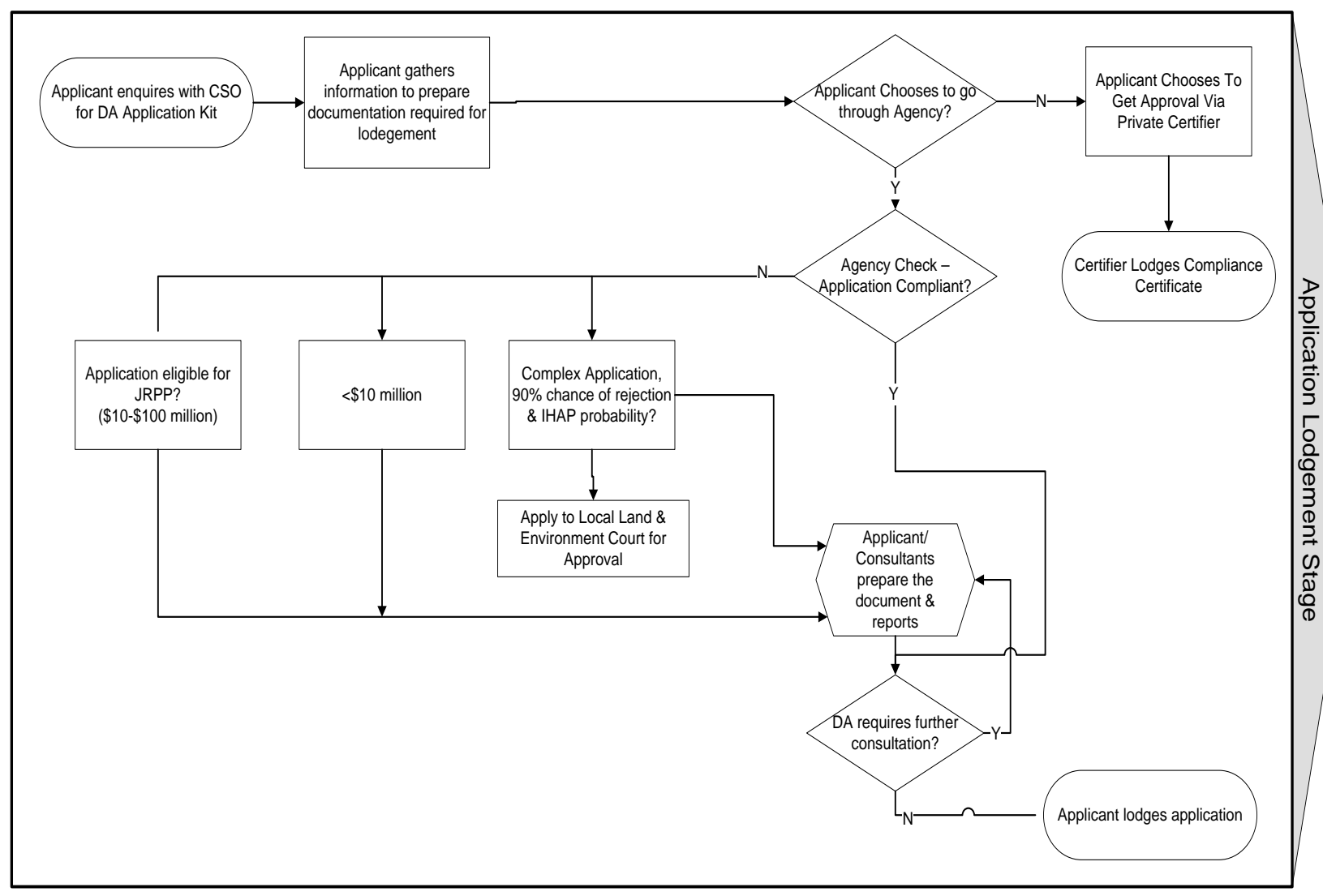

Figure III. Application Preparation Process Map

To further illustrate the value and use of SNA, we now present Figure III, which is the process map for the third process stage - Application Preparation (AP) - within prelodgement. Within this process, the applicant must gather information and prepare all documents described in the DA checklist provided to them by the customer service officer, or downloaded from the agency website. Consultation concerning application lodgement (excluding its preparation) or selection of the appropriate checklist is available through the Customer Service Centre (CSC) either by phone or in person. After gathering information and preparing documents in accordance with the requirements of the agency, an applicant then chooses to directly go through the agency or to seek approval through a private certifier. If the Certifier approves a proposal, then the Certifier lodges a compliance certificate with agency Z. When an applicant chooses to take the application directly through the agency, the agency completes a compliance check. At this stage, non-compliance means an application is incomplete and needs further work prior to submission and/or for various reasons may need to be directed to other community panels. 
For compliant applications, such as in some simple domestic DA's for example, the path to formal application then only entails a further check whether or not additional consultation may be required. For non-compliant applications, there are a number of different paths through which they may proceed. If an application's value is less than 10 million dollars it may still simply require more information and documentation preparation prior to lodgement. A further consideration involves whether an application is between 10 and 100 million dollars. If so, then it will also need to be directed to the Joint Regional Planning Panel (JRPP). Therein, the consultants engaged by an applicant may attempt to contact the JRPP members and discuss the feasibility of approval. This channel still requires the applicant to gather more information and prepare more documentation prior to lodgement. A further possibility is when an application is deemed complex with a high probability of rejection, regardless of dollar value. These applications may be eligible for an Independent Hearing and Assessment Panel (IHAP) and the applicant/consultants may choose to also submit the application to the Land and Environment Court for a determination in addition to agency $\mathrm{Z}$. Here again, this path still requires the applicant to gather more information and prepare more documentation prior to lodgement. Maximum effort at this preparation stage reduces the chance of error or requests for more information during the assessment phase.

Figure IV, depicts a much more complex process when the social network communications are mapped. It is important to note that the diagram depicts the social network communications surrounding a large development application. The focus of these communications experiences a shift depending on the size and scope of the application. For small and relatively straight-forward applications, the applicant is the focal point of communication. For larger more complex lodgements, consultants also form a central point of communication. In effect, 2 focal roles (Cotter, 1995) emerge depending on the complexity of the applications. At this stage, (as in the PM stage), there is a mix of formal and informal communications between stakeholders - with informal communications appearing to be almost double the formal. Strong and frequent communications have been observed between the applicant and consultants, who are engaged this time to manage the application. These stakeholders emerge as two key communication hubs for this stage of the application, with most if not all communications going back and forth to either one. However, there is minimal inclusion of agency $\mathrm{Z}$ in these communications and again, it could be the case that agency $\mathrm{Z}$ may experience some isolation from these processes (as in the PM stage) with resultant time lags incurred in the DA system processing times. 


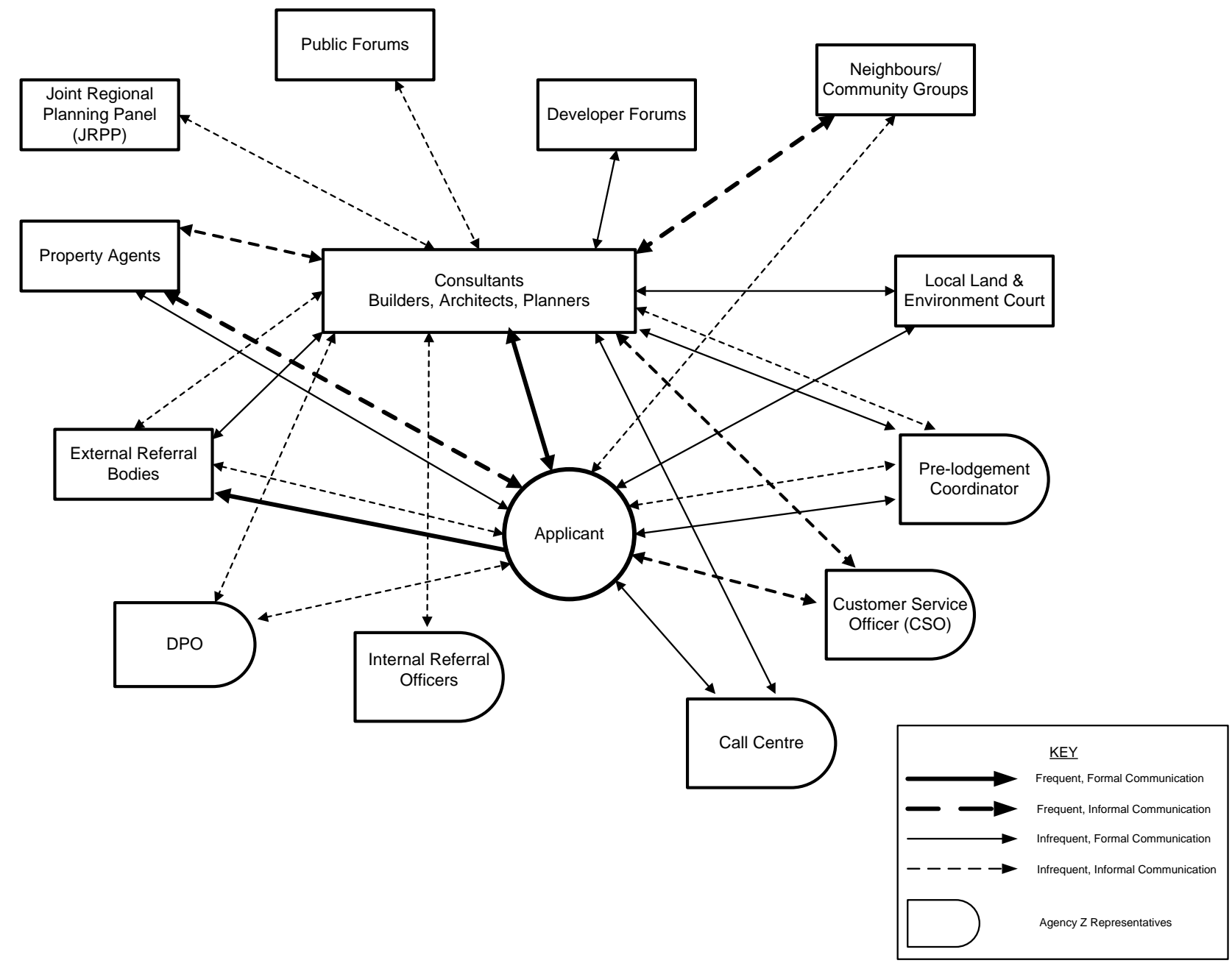

Figure IV. Application Preparation Social Network

The study of the AP stage serves to magnify some core observations made from the PM stage. Notably the SNA, together with the qualitative elements of the full study, uncovers otherwise underexposed social networks and the dynamics associated with them. As observed in Figure IV, one might question whether the applicant should be in a focal role given likely inexperience with the system and in collecting data and working with the myriad of stakeholder groups. Would agency $\mathrm{Z}$ indeed be better off assuming a focal role in this process where they act as the key liaison between the applicant and the other stakeholders? This point may seem provocative but nonetheless highlights a system perspective where indeed one should challenge accepted norms that an applicant must be assumed in or assumes a focal role in such a complex communication system. How many time delays and quality variations occur in the system simply due to the applicant's inexperience or lack of knowledge concerning the DA process? 
Moreover, as also depicted in Figure IV, one can identify and consider the impact of absent relationships or connections between stakeholders in the social network. For example, there are no communications on the circumference of the diagram i.e. between the Pre-lodgement Coordinator, the CSO, the Call Centre and the Local Land and Environment Court. This lack of connection might indeed be valid for current systems level performance but on the other hand, may also present opportunities to further innovate the system through improving communications and reducing times to progress matters relating to the service.

Figure IV, also highlights another consideration concerning the size and status of the external stakeholders and how significant is their hegemony on the social network. This of course can be of concern for the agency involved in providing the service as their influence over the progress of the DA applications may indeed be mute. In some part, this concern may add weight to an argument for the agency to be more actively involved in the external communications so that they can maintain a positive influence on the overall system performance and development rather the system performance be a victim to others predilections.

Based on the SNA, other considerations may involve considering external referral bodies as major stakeholders (depicted by formal and frequent communications) and for them to be actively included in any service system level innovation efforts. Moreover, particularly given the number and diversity of stakeholders involved in the system, it is imperative that agency $\mathrm{Z}$ effectively communicate their processes and policies to these parties and ensure consistency in their deployment. This service provision is closely linked to the applicant and is often a first point of significant contact with the agency. Hence, it is important that the agency creates a sufficient understanding and expectation of their service role with the client body. SNA is one crucial first step in acknowledging and understanding these complex relationships impacting a service provision and provides a basis for ongoing innovation that is truly systems linked. 


\section{Implications for research and social practice in Local Government service networks}

The analysis of the pre-lodgement process articulated in this paper has led the LG agency involved to a better understanding of their processes and critically, the stakeholder relationships in play. Significantly, as a result of this study, the agency then requested a follow up study to process benchmark their entire pre-lodgement process with a number of similar agencies in the state and the SNA was a core part of that benchmarking activity. Therein, the 'real' practice elements and social networks of those systems across those organizations were compared and contrasted and revealed quite similar and complex social network structures in operation.

In addition to the immediate benefits from the use of SNA in the case study examined, there are some broader implications for research at the local government level that can be posited from this work. The matter of taking a systems thinking or socio-technical systems approach towards investigating phenomena within the LG context - may be quite different and very challenging for those researchers more comfortable with positivist approaches e.g. some systems researchers. These alternative approaches may challenge a researcher's ontological and epistemological perspectives as they embrace the dynamic complexity of a system's interacting elements and include the human and social relationships within that frame. Through that inclusion, new possibilities or lenses through which we can analyse phenomena emerge and a researcher may necessarily be exposed to a range of cross disciplinary human and social theories that extend well beyond any narrow confines of their discipline's traditional theoretical base. For some positivist researchers, this may be too challenging to embrace. For other constructivist researchers, it serves to further heighten attention towards the social and human aspects of systems and how they interplay with the technical elements In that way, this study serves as an example of research in the LG sector that helps to move the field forward through illustrating and encouraging the employment of different theoretical perspectives and alternative approaches and tools to understand phenomena in LG operations. Consequently, it helps open up a more complex but likely more fruitful front for LG services research and development.

With respect to the implications for social practice in LG service networks, the findings presented in this paper serve to highlight the very real operational implications of better 
appreciating, understanding and engaging effectively with the actual social systems in-play in a service operation. Specifically, undertaking SNA in LG service environments can:

(i) Highlight potential non-compliance.

(ii) Identify opportunities to make positive structural changes to social and technical processes and to improve knowledge exchanges between the service provider and a myriad of external stakeholders.

(iii) Identify the extent and strength of the interface between a service provider and its external stakeholders.

(iv) Identify the strength and scope of social connections between external stakeholders involved in the system.

(v) Help identify functional roles in the service system that could better act as knowledge exchange hubs between the service provider and external stakeholders.

(vi) Enable participants within a service system to modify their communication behaviours/patterns in an informed way to more positively influence the efficacy and/or responsiveness of the entire system.

Moreover, in seeking to effectively redesign any service operation in LG, the potential significance of the internal and external (to the organization) stakeholders' relationships and the interplays of their communications and interactions cannot be understated. As observed in the case study presented here, the applicant, who may well have little understanding of the system, is ultimately placed in a focal role (and may in fact have had this role thrust upon them). This observation resulting from the analysis of the social network has identified a potentially substantial flaw in the system, which could in fact be the cause of significant system wide inefficiencies. Ultimately, such revelations and understandings may also translate into new policy initiatives and improved programs of engagement with relevant LG community groups that better utilise the extant social capital (Boxall and Purcell, 2008) to improve service delivery and reduce costs.

\section{Concluding Remarks}

This paper has provided an empirical LG case example of the value and use of SNA in creating a richer environment for service network innovation and development - wherein at present there appears to be a dearth of such empirical studies. It is also a case in which the 
social system involved traverses different 'external to the agency' organisations and internal organisational business units - a complex social network situation often prominently seen in government service operations. Based on this study and its outcomes, it is our general contention that SNA appears to constitute an essential complementary development framework to deploy so as to improve service operations in any organization. Therein, a SNA opens up the opportunities for management and system participants alike to jointly redesign a system's communication and interaction arrangements and structures in collaboration with the technical systems so that combined, they drive more holistic and sustainable service system improvement.

Given our general contention here is based on one singular case study, and to help build intellectual momentum and practical action on this issue, it would be desirable for other researchers to further investigate the value and use of SNA across a range of different service industries or operations. Of particular interest would be action research on systems where extensive inter-organisational collaboration and/or customer involvement in the service delivery is paramount in providing high quality and timely service to consumers. 


\section{References}

Ackoff, R., L. 1999. Ackoff's Best: His Classic Writings on Management. New York: Wiley.

Abdulmalek, F. A., \& Rajgopal, J. 2007. Analyzing the benefits of lean manufacturing and value stream mapping via simulation: A process sector case study. International Journal of Production Economics, 107, 223-236.

Antony, J. 2006. Six Sigma for Service Processes. Business Process Management, 12(2), 234-248.

Attefalk, L. \& Langervik, G. 2001. SocioTechnical Soft Systems Methodology - a sociotechnical approach to Soft Systems Methodology. Masters Thesis, Department of Informatics, University of Gothenburg.

Australian Government Report. 2010. Empowering Change: Fostering Innovation in the Australian Public Service.

Bhagat, V., Pepper, M. \& Sense, A. 2009. Agency Z Internal Report.

Biazzo, S. 2002. Process Mapping Techniques and Organisational Analysis: Lessons from Sociotechnical System Theory. Business Process Management Journal, 8(1), 42-52.

Borgatti, S.P. \& Li, X. 2009. On network analysis in a supply chain context. Supply Chain Management, 45(2), 5-22.

Boxall, P. \& Purcell, J. 2008. Strategy and Human Resource Management. China: Palgrave Macmillan.Checkland, P. 1981. Systems Thinking, Systems Practice. Chichester: Wiley.

Cherns, A.B. 1976. The Principles of Sociotechnical Design. Human Relations, 9(8), 783-92.

Chow, W. S. 2004. The quest for e-fulfilment quality in supply chain. International Journal of Quality and Reliability Management, 21(3), 319-328.

Correa, H. L., Ellram, L. M., Scavarda, A. J., \& Cooper, M. C. 2007. An operations management view of the service and goods offering mix. International Journal of Operations and Production Management, 27(5), 444-463.

Cotter, J. 1995. The 20\% Solution-Using Rapid Redesign to Create Tomorrow's Organisations Today. New York: Wiley.

Deming, W., E. 2000. Out of the Crisis. Cambridge: MIT Press.

Eisenhardt, K. M. 1989. Building theories from case study research. Academy of Management Review, 14(4), 532-550.

Evans, J. \& Lindsay, W. 2010. Managing for Quality and Performance Excellence, 8th Edition. Ohio: South-Western/Cengage Learning. 
Flyvbjerg, B. 2001. Making social science matter: Why social inquiry fails and how it can succeed again. Cambridge: Cambridge University Press.

Forrester, J. W. 1999. Industrial Dynamics. Waltham, MA: Pegasus Communications.

Fung, P. \&Wong, A. 1998. Case Study: Managing for total quality of logistics services in the supply chain. Logistics Information Management, 11(5), 324-329.

Gattorna, J. 2006. Living supply chains. Harlow: Financial Times Prentice Hall.

Gummesson, E. 1991. Qualitative methods in management research. Newbury Park: Sage Publications.

Herron, C. \& Braiden, P. M. 2006. A Methodology for Developing Sustainable Quantifiable Productivity Improvement in Manufacturing Companies. International Journal of Production Economics, 104(1), 143-153.

Ingram, H. 2000. Using Soft Systems Methodology to Manage Hotels: a case study. Managing Service Quality, 10(1), 6-9.

Johnston, R. 2005. Service operations management: from the roots up. International Journal of Operations and Production Management, 25(12), 1298-1308.

Joiner, B.L. 1994. Fourth Generation Management. New York: McGraw-Hill.

Klotz, L., Horman, M., Bi, H. H. \& Bechtel, J. 2008. The impact of process mapping on transparency. International Journal of Productivity and Performance Management, 57(8), 623-636.

Krajewski, L., Ritzman, L. \& Malhotra M. 2010. Operations Management: Processes and supply chains. New Jersey: Pearson.

Maani, K. E. \& Cavana, R. Y. 2007. Systems Thinking, Systems Dynamics: Managing Change and Complexity, 2nd Edition. North Shore: Pearson-Prentice Hall.

McGrath, R. Jnr. \& Sparks, W.L. 2005. The importance of building social capital. Quality Progress, 38(2), 45-49.

Min, S., Roath, A., Daugherty, P., Genchev, S., Chen, H., Arndt, A. \& Richey, R. 2005.

Supply chain collaboration: What's happening? The International Journal of Logistics Management, 16(2), 237-256.

Pfeffer, J. 1995. People, capability and competitive success. Management Development Review, 8(5), 6-10.

Piercy, N. \& Rich, N. 2009. Lean transformation in the pure service environment: the case of the call service centre. International Journal of Operations and Production Management, 29(1), 54-76. 
Prajogo, D. 2006. The implementation of operations management techniques in service organisations: An Australian perspective. International Journal of Operations and Production Management, 26(12), 501-513.

Prajogo, D. 2007. Operations management activities and operational performance in service firms. International Journal of Services Technology Management, 8(6),1460-6720.

Roth, A.V. and Menor, L. 2003. Insights into service operations management: a research agenda. Production and Operations Management, 12(2), 145-64.

Sense, A.J. 2007. Cultivating Learning Within Projects. Basingstoke: Palgrave Macmillan.

Sense, A.J. 2009. The social learning character of projects and project teams. International Journal of Knowledge Management Studies, Special Issue on knowledge management in the project work context, 3(3), 195-208.

Sense, A.J. \& Clements M.D. 2007. Learning to integrate: Supply chains reconceptualised. International Journal of Learning and Change, Special issue on supply chain learning and change, 2(2), 130-44.

Sense, A.J. \& Clements M.D. 2010. Socially shaping supply chain integration through learning. International Journal of Technology Management, Special issue on social innovation, 51(1), 92-105.

Sense,A. J. \& Pepper M. 2012. Social networks, social learning and service systems improvement. The Asia Pacific Journal of Public Administration, 34(1), 95-111.

Sterman, J. 2000. Business Dynamics: Systems Thinking and Modeling for a Complex World. Boston: Irwin/Mcgraw-Hill.

Taylor, F., W. 2007. The Principles of Scientific Management. Filiquarian Publishing.

Taylor, J. \& Felton, D. 1993. Performance by design: Sociotechnical systems in North America. New Jersey: Prentice Hall.

Trist, E.L. \& Bamforth, K.W. 1951. Some social and psychological consequences of the Longwall method of coal-getting: An Examination of the Psychological Situation and Defences of a Work Group in Relation to the Social Structure and Technological Content of the Work System. Human Relations, 4, 3-38.

Wisner, J., \& Stanley, L. 2008. Process Management: Creating Value Along the Supply Chain. Thomson South-Western.

Yang, H. M., Choi, B. S., Park, H. J., Suh, M. S., \& Chae, B. 2007. Supply chain management six sigma: a management innovation methodology at the Samsung Group. Supply Chain Management: An International Journal, 12(2), 88-95.

Yin, R.K. 1994. Case study research: Design and methods, 2nd edition. California: Sage. Zaklad, A., McKnight, R., Kosansky, A. \& Piermarini, J. 2004. The social side of the supply chain. Industrial engineer, 36(2), 40-47. 


\section{Author Biographies}

\section{Dr. Matthew Pepper}

Matthew Pepper is a Lecturer in the School of Management and Marketing and a member of the Institute for Innovation in Business and Social Research (IIBSoR), Faculty of Commerce, University of Wollongong. His primary areas of interest are continuous improvement, operations and supply chain management. Recent research and consultancy activities include continuous improvement and systems thinking, focusing on the implementation of quality management strategy and process improvement in local government and service environments.

\section{Associate Professor Andrew J. Sense}

Andrew Sense is an Associate Professor within the School of Management and Marketing at the University of Wollongong, Australia. He possesses senior managerial manufacturing and project management experience involving 18 years in Australian manufacturing industry. One primary research interest is centred on understanding the social operating environments of projects and he has published numerous papers on this in the fields of project management, workplace learning, knowledge management and research methodology. Another primary research interest revolves around building the innovation and learning capabilities within organisations. His more recent publications concern the dynamics of learning within project environments and on utilizing relational capital to improve service chain integration and performance. 